\title{
Single-port sympathectomy for palmar hyperhidrosis with Vasoview Hemopro 2 endoscopic vein harvesting device
}

\author{
Calvin S. H. Ng, MD, FRCS(CTh), Eugene C. L. Yeung, MBBS, FRCS(CTh), \\ Randolph H. L. Wong, MBChB, FRCS(CTh), and Micky W. T. Kwok, MBChB, MRCS, \\ Hong Kong, China
}

\begin{abstract}
Video-assisted thoracic surgery (VATS) sympathectomy is a well-accepted and definitive treatment for primary palmar hyperhidrosis, with a high success rate and low recurrence. The 3-port VATS approach typically uses 5- to 10-mm instruments or needlescopic 3-mm instruments. ${ }^{1}$ The Vasoview Hemopro 2 (MAQUET Medical Systems, Wayne, $\mathrm{NJ}$ ) endoscopic vein harvesting device has a 7-mm highdefinition thoracoscope, a parallel working channel for the Hemopro 2 dissector and automatic shut-off heat-sensing technology, a built-in $\mathrm{CO}_{2}$ gas insufflation channel, and a retractable lens-cleansing system all encompassed into one instrument, allowing simple single-port VATS procedures (Figure 1). The potential advantages are increased patient acceptance, minimal access trauma, reduced postoperative discomfort, and increased aesthetics. We present an innovative technique of VATS sympathectomy for palmar hyperhidrosis using the single-port Vasoview Hemopro 2 device.
\end{abstract}

\section{CLINICAL SUMMARY}

A 27-year-old woman who was referred for primary palmar hyperhidrosis underwent single-port bilateral Vasoview sympathectomy. She received general anesthesia and was intubated with a double-lumen endobronchial tube. In the supine position with both arms abducted 90 degrees, the operating table was flexed so that the patient was sitting up at approximately 20 degrees to allow the lung to fall away from the apex. A 1-cm left chest wall axillary incision was made posterior to the lateral border of the pectoralis major muscle in the third intercostal space. Left lung deflation was confirmed before entering the pleural space, and digital exploration confirmed the absence of pleural adhesions. The VasoView device (without port) was inserted into the thoracic cavity under thoracoscopic vision (Figure 2). Low-pressure $(6 \mathrm{~mm} \mathrm{Hg}) \mathrm{CO}_{2}$ pneumothorax was achieved via insufflation through an inbuilt channel in the device to

\footnotetext{
From the Department of Surgery, Prince of Wales Hospital, The Chinese University of Hong Kong, Hong Kong SAR, China.

Disclosures: Authors have nothing to disclose with regard to commercial support.

Received for publication Dec 14, 2011; revisions received May 19, 2012; accepted for publication June 12, 2012; available ahead of print July 6, 2012.

Address for reprints: Calvin S. H. Ng, MD, FRCS(CTh), Division of Cardiothoracic Surgery, The Chinese University of Hong Kong, Prince of Wales Hospital, Shatin, NT, Hong Kong SAR, China (E-mail: calvinng@surgery.cuhk.edu.hk)

J Thorac Cardiovasc Surg 2012;144:1256-7

$0022-5223 / \$ 36.00$

Copyright (C) 2012 by The American Association for Thoracic Surgery

http://dx.doi.org/10.1016/j.jtcvs.2012.06.020
}

improve lung collapse, particularly in the single-port procedure in which there are no additional instruments to manipulate the lung. By using the Hemopro dissector, the second and third sympathetic ganglions and associated nerve segments, as well as the fibers of Kuntz, were transected and thermally ablated. ${ }^{2}$ Condensation or blood contamination of the lens can be removed by the inbuilt hydro-cleansing instrument. Hemostasis was secured, and a long suction catheter was placed into the working port of the Vasoview device and directed into the apex. The device was withdrawn until it just remained within the thoracic cavity, and the lung was inflated under thoracoscopic vision, with a 10-second inspiratory hold as suction was applied to the catheter, which was subsequently withdrawn. The procedure was repeated on the right side. The total operative time for the bilateral procedure was 62 minutes with minimal blood loss. There was no residual hyperhidrosis after surgery, and she was discharged later in the day. Her visual analogue pain score at discharge was 2.2. No compensatory hyperhidrosis or recurrence was detected at 3 months follow-up.

\section{DISCUSSION}

The Vasoview device is widely used for endoscopic vein and artery harvesting for coronary artery bypass graft surgery. ${ }^{3}$ The incorporation of a 7 -mm high-resolution endoscope, a parallel working channel for the Hemopro 2 dissector, a built-in $\mathrm{CO}_{2}$ gas insufflation channel, and a retractable lens-cleansing system into the $12-\mathrm{mm}$ diameter Vasoview device allows it to be used for simple intrathoracic procedures. An advantage of the Vasoview device's inbuilt retractable lens cleansing system is that it obviates the need for repeated endoscope withdrawal for fogging from condensation. Furthermore, the Hemopro 2 dissecting grasper is the latest-generation dissecting instrument that has a unique thermostatic design with cut and seal capabilities and well-insulated tips that minimize adjacent tissue thermal spread to less than $1 \mathrm{~mm}$. The design of the Hemopro 2 dissector with Starion technology (Starion Instruments, Sunnyvale, Calif) uses a gradated thermal tip and pressure to cut and coagulate without electric current passing through tissues, which is an improvement from the unprotected tips of the Vasoview 7XS diathermy scissors device originally described by Bouma and colleagues. ${ }^{4}$ Such design is important in reducing collateral thermal tissue damage ${ }^{5}$ and in the context of sympathectomy might reduce the risk of inadvertent superior sympathetic chain 


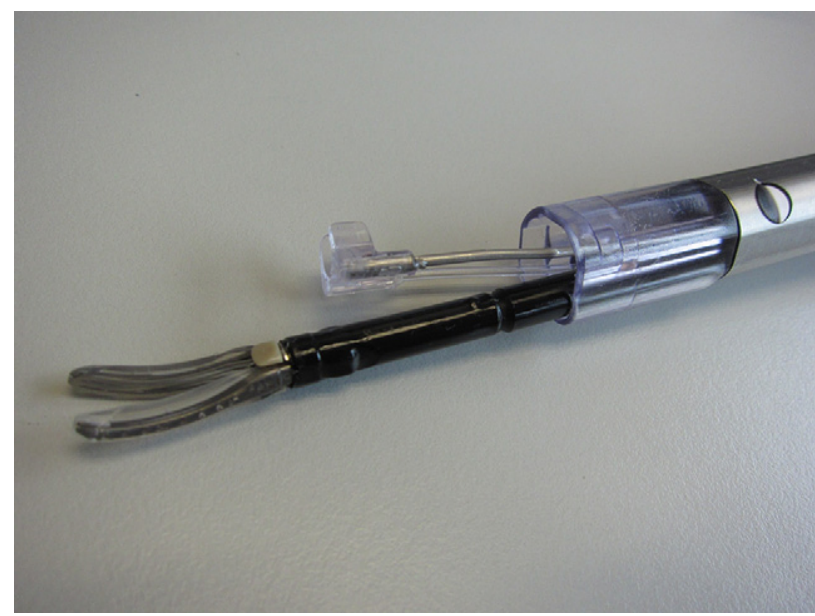

FIGURE 1. Instrumentation at the end of the Hemopro 2 Vasoview device (MAQUET Medical Systems, Wayne, NJ).

injury and associated complications, including Horner's syndrome. In addition, the combined features of the Vasoview device allow a single surgeon to perform the sympathectomy, being both the thoracoscopic camera holder and the operator. Our preferred supine patient position makes redraping or repositioning during the bilateral procedure unnecessary, saving time and reducing wound contamination risks. A potential disadvantage of the single-port approach is the limited ability to deal with pleural adhesions and bleeding from chest wall vessels.

\section{CONCLUSIONS}

Single-port VATS sympathectomy for palmar hyperhidrosis with the Vasoview Hemopro 2 device can be performed safely, with minimal chest wall access trauma and satisfactory cosmesis results, without compromising the early surgical outcomes. The long-term outcomes and

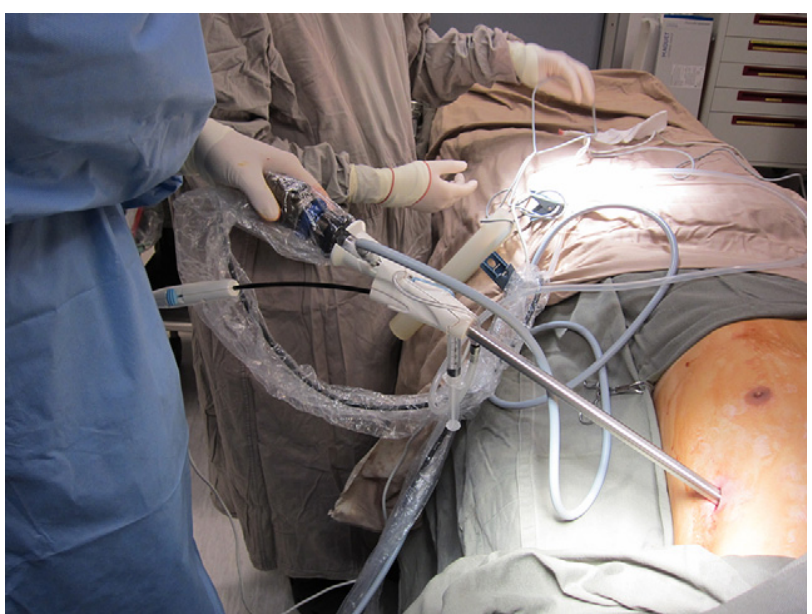

FIGURE 2. Operating room photograph illustrating the position, Vasoview device, and surgical access for sympathectomy.

potential benefits of this single-port technique warrant further investigation.

\section{References}

1. Yim AP, Liu HP, Lee TW, Wan S, Arifi AA. 'Needlescopic' video-assisted thoracic surgery for palmar hyperhidrosis. Eur J Cardiothorac Surg. 2000;17: 697-701.

2. Miller DL, Bryant AS, Force SD, Miller JI Jr. Effect of sympathectomy level on the incidence of compensatory hyperhidrosis after sympathectomy for palmar hyperhidrosis. J Thorac Cardiovasc Surg. 2009;138:581-5.

3. Zenati MA, Shroyer AL, Collins JF, Hattler B, Ota T, Almassi GH, et al. Impact of endoscopic versus open saphenous vein harvest technique on late coronary artery bypass grafting patient outcomes in the ROOBY (Randomized On/Off Bypass) Trial. J Thorac Cardiovasc Surg. 2011;141:338-44.

4. Bouma W, Klinkenberg TJ, Mariani MA. Bilateral single-port thoracoscopic sympathectomy with the VasoView device in the treatment of palmar and axillary hyperhidrosis. Interact Cardiovasc Thorac Surg. 2011;12:106-9.

5. Rojas-Pena A, Koch KL, Heitner HD, Hall CM, Bergin IL, Cook KE. Quantification of thermal spread and burst pressure after endoscopic vessel harvesting: a comparison of 2 commercially available devices. $J$ Thorac Cardiovasc Surg. 2011;142:203-8.

\title{
Posterior pulmonary artery bifurcation side-to-side arterioplasty for branch pulmonary artery stenosis
}

\author{
Jenelle A. Holst, BA, ${ }^{a}$ David N. Campbell, MD, ${ }^{\text {a,b }}$ James Jaggers, MD,,${ }^{a, b}$ and Max B. Mitchell, MD, ${ }^{\text {a,b }}$ \\ Aurora, Colo
}

\footnotetext{
From the University of Colorado Denver School of Medicine, ${ }^{\text {a }}$ Aurora, Colo; and Children's Hospital Heart Institute, ${ }^{\mathrm{b}}$ Aurora, Colo.

Disclosures: Authors have nothing to disclose with regard to commercial support.

Received for publication Jan 25, 2012; revisions received May 13, 2012; accepted for publication June 12, 2012; available ahead of print July 2, 2012.

Address for reprints: Max B. Mitchell, MD, Children's Hospital Colorado Heart Institute, 13123 East 16th Ave, B-200, Aurora, CO 80045 (E-mail: max.mitchell@ childrenscolorado.org).

J Thorac Cardiovasc Surg 2012;144:1257-9

$0022-5223 / \$ 36.00$

Copyright (c) 2012 by The American Association for Thoracic Surgery

http://dx.doi.org/10.1016/j.jtcvs.2012.06.021
}

Right ventricular outflow tract (RVOT) reconstructions involving a right ventricle to pulmonary artery (RV-PA) conduit or transannular patch almost universally obligate subsequent pulmonary valve replacement. ${ }^{1}$ In some patients, ostial branch pulmonary artery stenosis (BPAS) requires repair concomitantly with pulmonary valve replacement. ${ }^{2}$ Growth after repair early in life displaces the pulmonary artery bifurcation anteriorly, resulting in an abnormally parallel course of the proximal branch 